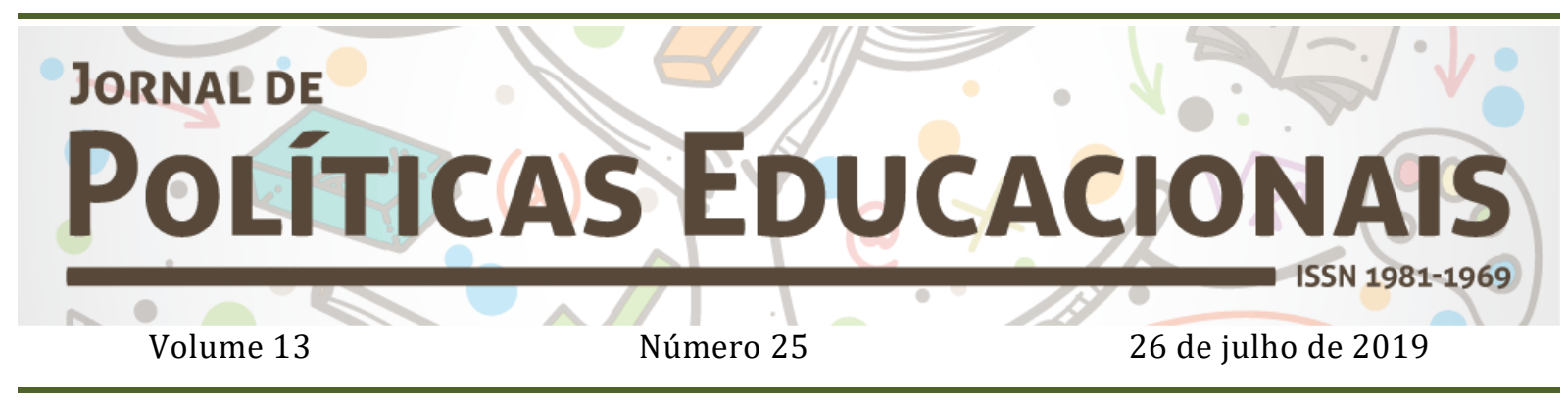

\title{
A dinâmica do acesso à educação superior brasileira: do público ao privado
}

\section{The dynamics of access to Brazilian higher education: from public to private}

\section{La dinámica del acceso a la educación superior brasileña: del público al privado}

\author{
Edineide Jezine ${ }^{1}$ \\ Jailson Batista dos Santos ${ }^{2}$
}

Citação: JEZINE, E.; SANTOS, J. B. dos. A dinâmica do acesso à educação superior brasileira: do público ao privado. Jornal de Políticas Educacionais. V. 13, n. 25. Julho de 2019.

http:// 10.5380/ipe.v13i0.64492

Resumo:

0 presente artigo tem como objetivo discutir a relação entre o público e o privado no âmbito do acesso às Instituições de Educação Superior Brasileiras (IES), a partir da descrição do número de instituições, ingressantes, oferta de vagas e matrículas em nível de Brasil, Nordeste e Paraíba, considerando os impactos gerados pelas políticas públicas de acesso no contexto neoliberal. Fundamentamos a discussão em dados do Censo da Educação Superior (INEP) - (2010-2017) e em pesquisas desenvolvidas pelo Grupo de Estudos e Pesquisas em Educação Superior e Sociedade (GEPESS/UFPB) - (CASTELO BRANCO; JEZINE; NAKAMURA, 2015), dente outras fontes. Os resultados apontam que o processo de expansão das IES brasileiras apresenta um crescimento significativo de ingressantes na rede privada, no âmbito nacional, regional e local. Tal crescimento representa os impactos das políticas de acesso que, ao longo dos anos, vêm reforçando a supremacia do setor privado sobre o público, acompanhando a lógica do projeto neoliberal. Palavras-chaves: Acesso. Educação Superior. Políticas Públicas. Público e Privado

\footnotetext{
1 Doutora em Sociologia pela Universidade Federal de Pernambuco (UFPE). Professora Titular da Universidade Federal da Paraíba com atuação no ensino, pesquisa e extensão, na Graduação e Pósgraduação. Coordenadora do Programa de Pós-Graduação em Políticas Públicas, Gestão e Avaliação da Educação Superior (MPPGAV). https://orcid.org/0000-0002-0180-0347 E-mail: edjezine@gmail.com ${ }^{2}$ Mestrando em Educação pelo Programa de Pós-Graduação em Educação (PPGE), da Universidade Federal da Paraíba (UFPB), na Linha de Pesquisa em Educação Popular. Graduado em Pedagogia com área de aprofundamento em Educação do Campo pela Universidade Federal da Paraíba (UFPB). Orcid: https://orcid.org/0000-0002-5669-2566 E-mail: jaylsonbatysta@gmail.com
} 
JENIZE, E; SANTOS, J. B. dos. A dinâmica do acesso à educação superior brasileira: do público ao privado

\begin{abstract}
:
The objective of this article is to discuss the relation between public and private in the scope of the Brazilian Higher Education Institutions (IES), based on the description of the number of institutions, entrants, vacancies and number of enrollments in Brazil, Northeast and Paraíba, considering the impacts generated by the public policies of access to higher education in the neoliberal context. We base the discussion on data from Inep (2010-2017) and on research developed by the Grupo de Estudos e Pesquisas em Educação Superior e Sociedade (GEPESS/UFPB) (CASTELO BRANCO; JEZINE; NAKAMURA, 2015). The results show that the expansion process of Brazilian IES shows a significant increase in enrollments in the private sector of education at the national, regional and local levels. Such growth represents the impacts of access policies that, over the years, have reinforced the private sector's supremacy over the public sector, following the logic of the neoliberal project.
\end{abstract}

Keywords: Access. College education. Public Policy. Public and Private.

\title{
Resumen:
}

El presente artículo tiene como objetivo discutir la relación entre lo público y lo privado en el ámbito de las Instituciones de Educación Superior Brasileñas (IES), a partir de la descripción del número de instituciones, ingresantes, oferta de vacantes y matrículas a nivel de Brasil, Nordeste y Brasil Paraíba, considerando los impactos generados por las políticas públicas de acceso a la educación superior en el contexto neoliberal. Los resultados apuntan que el proceso de expansión de las IES brasileñas presenta un crecimiento significativo de ingresantes en la red privada de enseñanza, en el ámbito Nacional, Regional y Local. Este crecimiento representa los impactos de las políticas de acceso que, a lo largo de los años, vienen reforzando la supremacía del sector privado sobre el sector público, acompañando la lógica del proyecto neoliberal.

Palabras claves: Acceso. Educación Universitaria. Políticas públicas. Público y Privado.

\section{Considerações iniciais}

A temática em que se processa a dinâmica do acesso à educação superior brasileira situa-se no debate acerca da supremacia do setor privado sobre o setor público, identificada na pesquisa intitulada "Políticas de Acesso e Permanência à Educação Superior: os impactos do Sisu e das políticas de cotas no contexto de inclusão na Universidade Federal da Paraíba" (SANTOS, 2017) ${ }^{3}$. A referida pesquisa dialoga com os debates fomentados pelo Grupo de Estudos e Pesquisas em Educação Superior e Sociedade (GEPESS/UFPB) e buscou responder a dinâmica da inclusão social na educação superior, considerando o acesso e a permanência de estudantes em situação de vulnerabilidade, econômica e educacional no contexto da expansão das universidades brasileiras.

As pesquisas realizadas pelo GEPESS, a partir do projeto sub 05 - Acesso e permanência na expansão da educação, revelaram mudanças no perfil dos estudantes que ingressaram no ensino superior por meio das políticas de cotas, uma vez que estas

\footnotetext{
${ }^{3}$ Pesquisa financiada pelo Conselho Nacional de Desenvolvimento Científico e Tecnológico (CNPq), que compõe o plano de trabalho intitulado: "Politicas de acesso à educação superior e o perfil sócio econômico dos ingressos pelo SISU e políticas de cotas em cursos de alto e baixo prestígio social na UFPB". O plano referido analisa as políticas de acesso no âmbito da Universidade Federal da Paraíba (UFPB) e caracteriza o perfil do ingresso a partir da implantação do SISU, a fim de apreender processos de inclusão e/ou exclusão social, e a proporção das desigualdades sociais nas áreas de conhecimento (SANTOS, 2017).
} 
JENIZE, E; SANTOS, J. B. dos. A dinâmica do acesso à educação superior brasileira: do público ao privado

contribuíram consideravelmente para o acesso de sujeitos em situação de vulnerabilidade a esse nível de ensino. No caso da UFPB, especificamente, os estudos apontaram que os períodos de implementação da Modalidade de Ingresso por Reserva de Vagas (MIRV) e, posteriormente, do Sistema de Seleção Unificada (Sisu) favoreceram o ingresso de estudantes oriundos de escolas públicas, passando de $36 \%$, no ano de 2008 , para 53,1\%, em 2012, expressando crescimento significativo entre esses períodos. (CASTELO BRANCO; JEZINE; NAKAMURA, 2017).

Como forma de dar continuidade às investigações, buscamos discutir a relação entre o público e o privado, no que tangue ao acesso à educação superior, a partir da descrição do número de instituições, ingressantes, oferta de vagas e número de matrículas registrados nesse nível de ensino, na relação Brasil, Nordeste e Paraíba, considerando, agora, os impactos gerados pelas políticas públicas de acesso (Fies e Prouni) no contexto neoliberal.

Para tanto, apoiamo-nos na metodologia qualitativa do tipo descritiva, amparada em dados estáticos do Censo da Educação Superior (INEP). Dos dados encontrados, recortamos o período de 2010 a 2017, por conta que, entre esse período, a UFPB atingiu o marco de duplicação de suas vagas em cursos de graduação presencial em decorrência das políticas de democratização do acesso, seguindo assim, a tendência nacional de expansão das Instituições de Ensino Superior (IES).

Partimos do pressuposto de que políticas públicas como o Fies e o Prouni podem gerar impactos significativos na relação público e privado, de modo a atender à lógica do contexto neoliberal e em consonância com a reestruturação capitalista. De acordo com Santos (2011), essa reestruturação configura-se como um fenômeno inserido no contexto da globalização em que sua estrutura necessita de sustentação, uma dinamicidade multidimensional, conectada às diversificadas esferas que compõem o nacional e o internacional ou o global e o local. Para Felinto (2015), o projeto neoliberal coaduna com a reforma do Estado brasileiro, tendo suas aproximações no governo Fernando Collor de Mello - (1990-1992), reafirmando-se na transição do governo Itamar Fraco (1993-1994) para o governo do Fernando Henrique Cardoso - FHC (1995-2002), dando continuidade no governo de Luís Inácio Lula da Silva - LULA (2003-2011).

Perpassando pelo governo Dilma (2012-2014), depois pelo governo Temer (2016 - 2018), o projeto neoliberal se intensifica na atual conjuntura política do presidente recentemente eleito, apresentando em seu discurso as possibilidades de privatizações no 
JENIZE, E; SANTOS, J. B. dos. A dinâmica do acesso à educação superior brasileira: do público ao privado

país. Dessa forma, adota-se um discurso direcionado à potencialização do sistema capitalista em consonância com o projeto neoliberal.

Atualmente, assistimos a uma série de desmontes na educação brasileira, como vetos em verba extra para a educação básica ${ }^{4}$; corte de verbas em universidades e institutos federais 5 ; previsão de redução de 30\% do investimento em educação6; dentre outros desmontes promovidos pelo atual governo. Ademais, outras medidas foram incrementadas para esse cenário, tais como a terceirização irrestrita; a reforma trabalhista; política de caça aos povos indígenas; abertura do pré-sal aos estrangeiros; privatizações ${ }^{7}$, dentre outras medidas. Essas mudanças representam um cenário repleto de retrocessos, colocando a educação em risco e sem perspectivas de um futuro melhor.

Diante do cenário apresentado, emerge a necessidade de avanço no debate acerca das políticas públicas de acesso à educação superior, bem como a relação estabelecida entre o setor público e privado no referido nível de ensino. Nesse sentido, a problemática que se segue parte do seguinte questionamento: quais os impactos das políticas públicas de acesso à educação superior na relação público e privado nos âmbitos nacional (Brasil), regional (Nordeste) e local (Paraíba)? Como se apresenta a dinâmica do acesso à educação superior frente ao contexto neoliberal?

Em consonância à problemática levantada, o presente texto encontra-se organizado em quatro tópicos, a começar por esta introdução, que apresenta algumas aproximações acerca do cenário da educação superior na perspectiva no contexto neoliberal; em seguida, apresentamos um panorama das políticas públicas de expansão do acesso à educação superior, como sendo de responsabilidade do Estado, para uma breve contextualização; posteriormente, expomos uma descrição analítica acerca da dinâmica do acesso no contexto da expansão das IES no Brasil, Nordeste e Paraíba, considerando a relação entre o público e o privado; e por último, apresentamos as considerações finais, expondo algumas inferências resultantes das discussões sobre a temática em foco.

\footnotetext{
${ }^{4}$ Fonte: ESTADÃO. Disponível em: <http://educacao.estadao.com.br/noticias/geral,temer-veta-verbaextra-paraeducacao-basica-ministro-fala-em-orcamento-realista,70002136603> Acesso em 18 dez. 2018. ${ }^{5}$ Fonte: G1. Disponível em: <https://g1.globo.com/educacao/noticia/veja-o-impacto-do-corte-deverbasem-universidades-e-institutos-federais-de-14-estados.ghtml>. Acesso em: 20 dez. 2018.

${ }^{6}$ Fonte: REVISTA FÓRUM. Disponível em: <https://www.revistaforum.com.br/2018-governo-temerreduziraem-mais-de-30-os-investimentos-em-educacao/>. Acesso em: 17 dez. 2018.

${ }^{7}$ Fonte: CARTA CAPITAL. Disponível em: <https://www.cartacapital.com.br/politica/12-retrocessos-em-

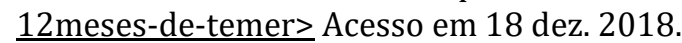




\section{Políticas Públicas de Expansão do Acesso à Educação Superior}

Com a aprovação da Lei de Diretrizes e Bases da Educação Nacional - LDB no 9393/1996, desencadeou-se uma série de reformas políticas no âmbito do ensino superior brasileiro nos últimos anos, tanto para o setor público como para o setor privado. Nesse contexto, destacam-se o Programa de Financiamento Estudantil (Fies), que tem por objetivo o financiamento para estudantes que desejam adentrar em IES privadas, e o Programa Universidade para Todos (Prouni), também em atendimento ao setor privado de ensino, ambos programas do Ministério da Educação. Tratam-se de políticas púbicas implementadas com o objetivo de favorecer a democratização do acesso à educação superior, na tentativa de diminuir as desigualdades sociais do país.

As políticas públicas são aqui compreendidas como as de responsabilidade do Estado - "quanto à implementação e manutenção a partir de um processo de tomada de decisões que envolvem órgãos públicos e diferentes organismos" (HOFLING; 2001; p.2). Assim, subtende-se que toda política pública deve ser pensada e estruturada com objetivos baseados no contexto da inclusão social e da garantia dos direitos humanos e sociais. Nessa direção, ressalta-se a importância de aprofundar as discussões acerca das políticas de acesso ao ensino superior, no contexto das desigualdades sociais, para uma melhor compreensão sobre a problemática do acesso, principalmente de sujeitos em situação de vulnerabilidade social.

A política destinada ao setor privado e para grupos socialmente desfavorecidos ocorre a partir de ações emergenciais de financiamento, instauradas nos anos 1990 no governo FHC, tendo sua continuidade no governo de Luís Inácio Lula da Silva (20032010). Como política de expansão ao setor público, destacam-se os Programas a “Expansão com Interiorização" (2003 - 2006) e o Plano de Reestruturação e Expansão das Universidades Federais (2007 - 2012). 0 primeiro emerge com intuito de possibilitar a expansão da educação superior por meio do fortalecimento de campi no interior dos estados brasileiros, o segundo atende ao objetivo de continuar com o projeto anterior, enfocando no aumento do acesso e promoção da permanência de sujeitos na educação superior, por meio do Decreto no 6.096, de 24 de abril de 2007, atendendo, assim, três dimensões: estrutura física, acadêmica e pedagógica. (BRASIL, 2007). 
JENIZE, E; SANTOS, J. B. dos. A dinâmica do acesso à educação superior brasileira: do público ao privado

Quadro 01 - Políticas Públicas de Acesso à Educação Superior Brasileira - (1995 - 2017)

\begin{tabular}{|c|c|c|}
\hline Políticas Públicas & Objetivos $^{8}$ & Beneficiários/favorecidos \\
\hline $\begin{array}{l}\text { Programa de Financiamento } \\
\text { Estudantil - FIES (governo } \\
\text { Fernando Henrique Cardoso } \\
(1995-2002) ; \text { Luiz Inácio } \\
\text { Lula da Silva (2003-2010); } \\
\text { Dilma Rousseff (2011-2015); } \\
\text { e Temer (2016-2017). }\end{array}$ & $\begin{array}{l}\text { Criado em 1999, o FIES é um } \\
\text { programa do Ministério da } \\
\text { Educação que tem por objetivo } \\
\text { o financiamento da graduação. }\end{array}$ & $\begin{array}{l}\text { Setor Privado - Destinado a } \\
\text { estudantes que desejam } \\
\text { adentrar em IES privadas. }{ }^{9}\end{array}$ \\
\hline $\begin{array}{l}\text { Programa Universidade para } \\
\text { Todos - PROUNI. } \\
\text { Fernando Henrique Cardoso } \\
(1995-2002) \\
\text { Luiz Inácio Lula da Silva } \\
(2003-2010) ; \text { Dilma Rousseff } \\
(2011-2015) ; \text { e Temer } \\
(2016-2017) .\end{array}$ & \begin{tabular}{l}
\multicolumn{3}{l}{ Criado em 200510 , o PROUNI é } \\
um Programa do Ministério da \\
Educação dedicado à \\
distribuição de de bolsas \\
integrais e parciais.
\end{tabular} & $\begin{array}{l}\text { Setor Privado - Destinado a } \\
\text { estudantes de baixa renda } \\
\text { que não tem formação } \\
\text { acadêmica e desejam } \\
\text { adentrar em instituições } \\
\text { privadas de ensino }{ }^{11} \text {. }\end{array}$ \\
\hline $\begin{array}{l}\text { Exame Nacional do Ensino } \\
\text { Médio - ENEM (governo } \\
\text { Fernando Henrique Cardoso } \\
(1995-2002), \text { Luiz Inácio } \\
\text { Lula da Silva (2003-2010); } \\
\text { Dilma Rousseff (2011-2015); } \\
\text { e Temer (2016-2017). }\end{array}$ & $\begin{array}{l}\text { Criado em 1998. Objetiva } \\
\text { avaliar o desempenho dos } \\
\text { estudantes que terminaram a } \\
\text { escola básica. }\end{array}$ & $\begin{array}{l}\text { Setor Público e Privado - } \\
\text { Destinado a estudantes que } \\
\text { estão cursando ou } \\
\text { concluíram o ensino médio. }\end{array}$ \\
\hline 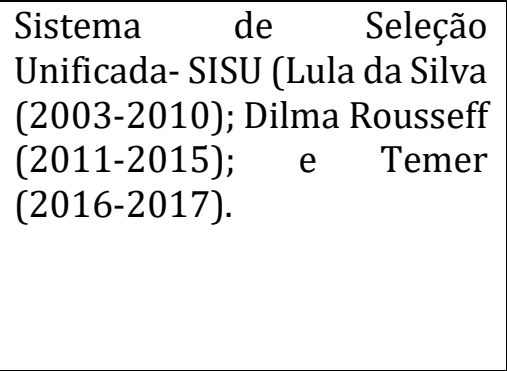 & $\begin{array}{l}\text { Regulamentado em 2012, por } \\
\text { meio da portaria normativa no } \\
21 \text {, de } 05 \text { de novembro de } \\
2012 \text {. Objetiva ampliar a } \\
\text { democratização do acesso às } \\
\text { vagas públicas do ensino } \\
\text { superior. }\end{array}$ & $\begin{array}{l}\text { Setor Público e Privado - } \\
\text { Oferta vagas, por meio do } \\
\text { seu sistema informatizado, } \\
\text { para os alunos que se } \\
\text { submeteram ao ENEM, a } \\
\text { todo estudante } \\
\text { regularmente matriculado } \\
\text { no ensino médio. }\end{array}$ \\
\hline $\begin{array}{l}\text { Reestruturação e Expansão } \\
\text { das Universidades Federais- } \\
\text { REUNI. SISU (Lula da Silva } \\
\text { (2003-2010); Dilma Rousseff } \\
\text { (2011-2015); e Temer } \\
(2016-2017) \text {. }\end{array}$ & $\begin{array}{l}\text { Vigora desde } 200712 \text {. Visa a } \\
\text { expansão das } \\
\text { federais riversidades } \\
\text { contemplando número de } \\
\text { vagas e cursos de graduação. }\end{array}$ & As IES Públicas e Privadas. \\
\hline
\end{tabular}

Fonte: Quadro elaborado a partir das informações atualizadas do site do MEC. Disponível em: <http://www.mec.gov.br/> Acesso em: 28/10/2018.

\footnotetext{
8 Todas as informações presentes na tabela foram retiradas do site disponível em: $<$ http://www.mec.gov.br/> Acesso em: 28/09/2018.

${ }^{9}$ Instituído pela Lei no 10.260 de 12 de Julho de 2001.

${ }^{10}$ A Lei do PROUNI no ano de 2005 tem como base a Lei n ${ }^{\circ} 9.870$ de 23 de novembro de 1990, considerado também como uma política do Governo FHC.

${ }^{11}$ Lei no 11.096 , de 13 de Janeiro de 2005.

${ }^{12}$ A partir do Decreto n ${ }^{\circ} 6.096$ de 2007.
} 
JENIZE, E; SANTOS, J. B. dos. A dinâmica do acesso à educação superior brasileira: do público ao privado

Ao observarmos as políticas públicas, expostas no quadro acima, percebe-se que os programas que visam o acesso à educação superior apresentam incentivo e fortalecimento ao setor privado de ensino, em atendimento às normatizações e recomendações do modelo de estado mínimo. Esses programas, apesar de se configurarem como políticas públicas favoráveis à democratização do acesso às IES, apoiam-se no discurso sob promessas de diminuição das desigualdades sociais no país, mas acaba atendendo os interesses do sistema capitalista, uma vez que favorece exclusivamente o setor privado de ensino (MANCEBO, 2015). Dessa forma, a expansão da educação superior no contexto neoliberal, atende a lógica mercantilista, reforçando a supremacia do privado sobre o público.

Em consonância às políticas de acesso, o cenário nacional, regional e local, nos períodos de 2010 a 2017, expressa a expansão da educação superior sobre o número de instituições criadas nos últimos sete anos. Fenômeno esse que teve seu início pós Lei de Diretrizes e Bases da Educação nacional (LDB 9394/96) e que, em seus 22 anos, oportunizou o crescimento do setor privado em instituições, vagas e matrículas (JEZINE; BITTAR, 2013). Nesse contexto, o aumento do número de instituições privadas no conjunto das Instituições de Ensino Superior (IES) se apresenta de forma expressiva, conforme ilustrado na Tabela 01 , a seguir.

Tabela 01 - Número de Instituições de Educação Superior (IES), segundo a Unidade da Federação e a Categoria Administrativa das IES - Brasil/Nordeste/Paraíba (2010 - 2017)

\begin{tabular}{c|c|c|c|c|c|c}
\hline \multirow{2}{*}{ Ano } & \multicolumn{1}{|l|}{ Brasil } & \multicolumn{2}{c|}{ Nordeste } & \multicolumn{2}{c}{ Paraíba } \\
\cline { 2 - 7 } & Público & Privado & Público & Privado & Público & Privado \\
\hline $\mathbf{2 0 1 0}$ & 278 & 2.100 & 64 & 369 & 4 & 33 \\
\hline $\mathbf{2 0 1 1}$ & 284 & 2.081 & 63 & 369 & 4 & 34 \\
\hline $\mathbf{2 0 1 2}$ & 304 & 2.112 & 65 & 379 & 4 & 33 \\
\hline $\mathbf{2 0 1 3}$ & 301 & 2.090 & 68 & 378 & 4 & 32 \\
\hline $\mathbf{2 0 1 4}$ & 298 & 2.070 & 67 & 385 & 4 & 33 \\
\hline $\mathbf{2 0 1 5}$ & 295 & 2.069 & 66 & 390 & 4 & 32 \\
\hline $\mathbf{2 0 1 6}$ & 296 & 2.111 & 66 & 414 & 4 & 36 \\
\hline $\mathbf{2 0 1 7}$ & 296 & 2.152 & 66 & 451 & 4 & 38 \\
\hline Cresc. \% & $\mathbf{6 , 5 \%}$ & $\mathbf{2 , 5 \%}$ & $\mathbf{3 , 1 \%}$ & $\mathbf{2 2 , 2 \%}$ & $\mathbf{0 \%}$ & $\mathbf{1 5 , 2 \%}$ \\
\hline
\end{tabular}

Fonte: BRASIL. INEP. Sinopses Estatísticas do Censo da Educação Superior: 2010 a 2017. Brasília: Disponível em: <http://portal.inep.gov.br/web/guest/sinopses-estatisticas-da-educacao-superior>. Acesso em 01 jul. 2018. 
JENIZE, E; SANTOS, J. B. dos. A dinâmica do acesso à educação superior brasileira: do público ao privado

No Brasil, verifica-se que, em 2010, constavam 278 IES públicas e 2.100 IES privadas; em 2017, o número de IES públicas subiu para 996, contra 2.152 de IES privadas. 0 crescimento em percentual de IES públicas ficou em 6,5\%, nas IES privadas chegou a 2,5\%, apesar disso não foi tão expressivo quando comparado esse crescimento a nível regional (Nordeste) e local (Paraíba). Na região Nordeste, o percentual de crescimento foi mais expressivo na rede privada, com 22,2\%, contra 3,1\% da rede pública; na Paraíba, o crescimento foi de $15,2 \%$ nas IES privadas, já na rede pública o número de instituições se manteve o mesmo no período analisado.

Pelos dados apresentados, percebe-se que o número de IES privadas no Brasil, Nordeste e Paraíba mantém-se em constante crescimento. Uma tendência percebida ao longos dos anos, em que se observa a reafirmação da supremacia do setor privado sobre o setor público, acompanhando a lógica do projeto neoliberal. Sobre essa lógica, Bernartt, Dickmann e Silva (2017) explicam que o neoliberalismo reproduz os ideais do sistema capitalista de modo puramente especulativo, com uma economia de caráter virtual e pósmoderna. Nesse sentido, dificulta-se a democratização das riquezas e a criação de novos empregos, promovendo a privatização dos lucros em detrimento dos altos custos pagos pela camada mais pobre da população. Trata-se, portanto, de uma forma de violência real que, a partir da lógica do capital, sustenta as relações de dominação e exploração. (BERNARTT; DICKMANN; SILVA, 2017).

Conforme exposto, há uma sintonia entre as ações empreendidas, pela via das políticas públicas de governo e os interesses do sistema capitalista, fazendo com que a educação seja tratada como mera mercadoria. Ademais, os efeitos das políticas de acesso no processo de expansão das Instituições de Educação Superior (IES) no Brasil encontram-se, também, na evolução das matrículas nos últimos sete anos, que se expressa em nível nacional, regional e local, conforme os dados da Sinopses Estatísticas do Censo da Educação Superior (INEP, 2010-1017), tabela 02, a seguir. 
JENIZE, E; SANTOS, J. B. dos. A dinâmica do acesso à educação superior brasileira: do público ao privado

Tabela 02 - Evolução das matrículas nos Cursos de Graduação Presenciais por Organização Acadêmica e Localização (capital e interior) - (2010 - 2017).

\begin{tabular}{|c|c|c|c|c|c|c|}
\hline \multirow{2}{*}{ Ano } & \multicolumn{2}{|c|}{ Brasil } & \multicolumn{2}{c|}{ Nordeste } & \multicolumn{2}{c|}{ Paraíba } \\
\cline { 2 - 7 } & Público & Privado & Público & Privado & Público & Privado \\
\hline $\mathbf{2 0 1 0}$ & 1.461 .696 & 3.987 .424 & 438.090 & 614.071 & 53.036 & 35.870 \\
\hline $\mathbf{2 0 1 1}$ & 1.595 .391 & 4.151 .371 & 471.209 & 667.749 & 62.328 & 39.319 \\
\hline $\mathbf{2 0 1 2}$ & 1.715 .752 & 4.208 .086 & 499.721 & 713.798 & 64.885 & 42.724 \\
\hline $\mathbf{2 0 1 3}$ & 1.932 .527 & 5.373 .450 & 561.175 & 960.531 & 71.366 & 59.767 \\
\hline $\mathbf{2 0 1 4}$ & 1.961 .002 & 5.867 .011 & 5 & 1.064 .031 & 74.412 & 69.777 \\
& & & 82.852 & & & \\
\hline $\mathbf{2 0 1 5}$ & 1.952 .145 & 6.075 .152 & 590.489 & 1.104 .191 & 75.880 & 77.736 \\
\hline $\mathbf{2 0 1 6}$ & 1.990 .078 & 6.058 .623 & 586.670 & 1.115 .008 & 74.297 & 79.195 \\
\hline $\mathbf{2 0 1 7}$ & 2.045 .356 & 6.241 .307 & 601.423 & 1.145 .233 & 72.234 & 83.354 \\
\hline Cresc. \% & $\mathbf{3 9 , 9 \%}$ & $\mathbf{5 6 , 5 \%}$ & $\mathbf{3 7 , 3 \%}$ & $\mathbf{8 6 , 5 \%}$ & $\mathbf{3 6 , 2 \%}$ & $\mathbf{1 3 2 , 4 \%}$ \\
\hline
\end{tabular}

Fonte: BRASIL. INEP. Sinopses Estatística do Censo da Educação Superior: 2010 a 2017. Brasília: Disponível em: <http://portal.inep.gov.br/superior-censosuperior-sinopse> Acesso em: 10 de out. 2018.

Os dados, acima, mostram que no Brasil as matrículas no período de 2010 até 2017, considerando os Governos Lula, Dilma e Temer, aumentaram em 39,9\%, no setor público, enquanto no setor privado o crescimento foi de 56,5\%. Observa-se um crescimento significativo do número de matrículas também na região Nordeste, em que o setor público chegou a $37,3 \%$, contra $86,5 \%$ de crescimento no setor privado.

Em que pese esse aumento na Paraíba, segue a tendência nacional e regional, sendo que, foi registrado $36,2 \%$ no setor público, contra $132,4 \%$ no privado, um crescimento bastante expressivo no número de matrículas do setor privado. Verifica-se, aí, crescimento entre o número de matrículas nos setores público e privado, em que o privado apresenta certa vantagem, quando comparadas a evolução das matrículas em nível nacional, regional e local.

Conforme assinalam Amaral e Chaves (2016, p. 59), a expansão do setor privadomercantil estimulada "pelas políticas implementadas pelos sucessivos governos, ao promoverem uma política de renúncia tributária e de financiamento direto aos estudantes, por meio do Prouni e do Fies, subvencionam parcela significativa de estudantes dessas instituições". Essas políticas que visam o acesso à educação superior têm contribuído com esse crescimento e, consequentemente, com essas disparidades identificadas na supremacia do privado sobre o público, a partir da transferência de recursos públicos e incentivos ficais.

\section{A dinâmica do acesso no contexto da expansão: a relação entre o público e o privado}


JENIZE, E; SANTOS, J. B. dos. A dinâmica do acesso à educação superior brasileira: do público ao privado

O fenômeno da expansão na educação superior brasileira tem se apresentado como um processo complexo, em que as políticas de expansão, a democratização do acesso e a permanência do alunado no ensino superior se entrelaçam em uma dinâmica única que envolve as políticas de educação superior e sua relação com a conjuntura do modelo de Estado neoliberal (PRESTES; JEZINE; SCOCUGLIA; 2012).

0 processo de expansão das IES brasileiras bem como as políticas públicas adotadas pelo governo federal com vista à democratização do acesso continuam surtindo efeitos também na evolução do número de vagas oferecidas, candidatos inscritos e ingressos nos cursos de graduação presenciais, segundo a unidade da federação e a categoria administrativa das IES do Brasil, conforme tabela 03 , a seguir.

Tabela 03 - Número de Vagas Oferecidas, Candidatos Inscritos e Ingressos nos Cursos de Graduação Presenciais, segundo a Unidade da Federação e a Categoria Administrativa das IES do Brasil (2010 - 2017)

\begin{tabular}{|c|c|c|c|c|c|c|}
\hline \multicolumn{7}{|c|}{ Brasil } \\
\hline \multirow[t]{2}{*}{ Ano } & \multicolumn{2}{|c|}{ Vagas Oferecidas } & \multicolumn{2}{|c|}{ Candidatos Inscritos } & \multicolumn{2}{|c|}{ Ingressos } \\
\hline & Público & Privado & Público & Privado & Público & Privado \\
\hline 2010 & 445.337 & 2.674 .855 & 3.364 .843 & 3.334 .059 & 408.562 & 1.181 .650 \\
\hline 2011 & 484.943 & 2.743 .728 & 5.138 .136 & 4.028 .451 & 426.597 & 1.260 .257 \\
\hline 2012 & 539.648 & 2.784 .759 & 6.577 .483 & 4.350 .292 & 462.097 & 1.508 .295 \\
\hline 2013 & 525.933 & 2.903 .782 & 7.232 .646 & 4.712 .433 & 457.206 & 1.494 .490 \\
\hline 2014 & 533.018 & 3.012 .276 & 8.157 .989 & 5.087 .807 & 452.416 & 1.658 .350 \\
\hline 2015 & 530.552 & 3.223 .732 & 8.517 .232 & 5.508 .890 & 451.174 & 1.493 .004 \\
\hline 2016 & 529.239 & 3.407 .890 & 7.904 .621 & 5.731 .131 & 457.288 & 1.400 .818 \\
\hline 2017 & 526.169 & 3.331 .403 & 7.458 .391 & 6.234 .832 & 456.947 & 1.419 .679 \\
\hline Cresc. \% & $18,2 \%$ & $24,5 \%$ & $121,7 \%$ & $87,0 \%$ & $11,8 \%$ & $20,1 \%$ \\
\hline
\end{tabular}

Fonte: BRASIL. INEP. Sinopses Estatísticas do Censo da Educação Superior: 2010 a 2017. Brasília: Disponível em: <http://portal.inep.gov.br/web/guest/sinopses-estatisticas-da-educacao-superior>. Acesso em 01 jul. 2018.

Os dados, acima, indicam que no ano de 2017 foram oferecidas 526.169 vagas em cursos de graduação em IES públicas, para essa oferta se inscreveram 7.458.391 candidatos e ingressaram 456.947. Em paralelo ao crescimento na relação de vagas ofertadas com o número de ingressantes, identifica-se 69.222 (15\%) de vagas não preenchidas. No tocante ao setor privado, o número de vagas ofertadas no respectivo ano consta em 3.331.403; candidatos inscritos, 6.234.832, e 1.419.679 ingressantes. Isso significa que o número de vagas não preenchidas no setor privado quando comparadas ao número de ingressos atinge 1.911.724, um percentual de 57,4\%. Nessa lógica, os 
JENIZE, E; SANTOS, J. B. dos. A dinâmica do acesso à educação superior brasileira: do público ao privado

números expressam uma quantidade significativa de vagas ociosas tanto na rede privada quanto na pública.

Sobre o problema apresentado acima, Castelo Branco, Jezine e Nakamura (2017) explicam que a tendência das vagas ociosas provoca um duplo processo de exclusão: o direito ao ensino de qualidade, e as condições de acesso desfavorável dos sujeitos em situação de vulnerabilidade social. Tendo em vista que metade da população brasileira possuem renda menor que um salário mínimo (IBGE, 2017), o que indica fator de dificuldade do cidadão manter-se em uma instituição privada, pode este, constitui-se a desistência da vaga conquistada.

Tabela 04 - Número de Vagas Oferecidas, Candidatos Inscritos e Ingressos nos Cursos de Graduação Presenciais, segundo a Unidade da Federação e a Categoria Administrativa das IES do Nordeste (2010 - 2017)

\begin{tabular}{|c|c|c|c|c|c|c|}
\hline \multicolumn{7}{|c|}{ Nordeste } \\
\hline \multirow[t]{2}{*}{ Ano } & \multicolumn{2}{|c|}{ Vagas Oferecidas } & \multicolumn{2}{|c|}{ Candidatos Inscritos } & \multicolumn{2}{|c|}{ Ingressos } \\
\hline & Público & Privado & Público & Privado & Público & Privado \\
\hline 2010 & 128.415 & 372.356 & 1.132 .222 & 487.156 & 121.333 & 178.617 \\
\hline 2011 & 140.828 & 383.875 & 1.683 .793 & 628.397 & 120.157 & 195.674 \\
\hline 2012 & 160.965 & 399.328 & 2.374 .894 & 726.025 & 126.848 & 236.738 \\
\hline 2013 & 147.281 & 432.511 & 2.288 .628 & 783.392 & 127.660 & 249.482 \\
\hline 2014 & 142.573 & 472.957 & 2.498 .550 & 952.017 & 127.538 & 290.353 \\
\hline 2015 & 143.428 & 520.643 & 2.756 .691 & 1.052 .866 & 125.964 & 263.443 \\
\hline 2016 & 145.349 & 575.242 & 2.692 .140 & 995.074 & 124.543 & 247.053 \\
\hline 2017 & 149.532 & 633.173 & 2.483 .701 & 1.150 .348 & 129.399 & 263.055 \\
\hline Cresc. \% & $16,4 \%$ & $70,7 \%$ & $119,4 \%$ & $136,1 \%$ & $6,6 \%$ & $47,3 \%$ \\
\hline
\end{tabular}

Fonte: BRASIL. INEP. Sinopses Estatísticas do Censo da Educação Superior: 2010 a 2015. Brasília: Disponível em: <http://portal.inep.gov.br/web/guest/sinopses-estatisticas-da-educacao-superior>. Acesso em 01 jul. 2018.

Ao delimitarmos nossa atenção às IES do Nordeste o número de vagas ofertadas na rede pública passou de 128.415, em 2010, para 149.532, em 2017, tendo um crescimento de 16,4\%. Na rede privada foram 372.356, em 2010, e em 2017 registrou 633.173, totalizando o percentual de 70,7\%, muito superior à rede pública. Em consonância a isso, o número de candidatos inscritos manteve-se acima do quantitativo de vagas ofertadas em todos os anos analisados. 
JENIZE, E; SANTOS, J. B. dos. A dinâmica do acesso à educação superior brasileira: do público ao privado

Tabela 05 - Número de Vagas Oferecidas, Candidatos Inscritos e Ingressos nos Cursos de Graduação Presenciais, segundo a Unidade da Federação e a Categoria Administrativa das IES da Paraíba (2010 - 2017)

\begin{tabular}{|c|c|c|c|c|c|c}
\hline \multirow{2}{*}{ Ano } & \multicolumn{7}{c}{ Vagas Oferecidas } & \multicolumn{2}{c}{ Candidatos Inscritos } & \multicolumn{2}{c}{ Ingressos } \\
\cline { 2 - 7 } & Público & Privado & Público & Privado & Público & Privado \\
\hline $\mathbf{2 0 1 0}$ & 17.315 & 19.890 & 142.527 & 23.562 & 16.153 & 11.458 \\
\hline $\mathbf{2 0 1 1}$ & 12.242 & 22.200 & 169.993 & 30.857 & 17.707 & 13.372 \\
\hline $\mathbf{2 0 1 2}$ & 19.698 & 24.111 & 267.844 & 37.347 & 19.783 & 14.555 \\
\hline $\mathbf{2 0 1 3}$ & 20.700 & 29.287 & 340.594 & 59.788 & 20.100 & 17.738 \\
\hline $\mathbf{2 0 1 4}$ & 20.354 & 34.186 & 302.743 & 64.325 & 19.079 & 22.467 \\
\hline $\mathbf{2 0 1 5}$ & 17.982 & 37.670 & 349.935 & 60.307 & 17.955 & 20.961 \\
\hline $\mathbf{2 0 1 6}$ & 20.921 & 40.710 & 286.156 & 78.351 & 17.789 & 18.269 \\
\hline $\mathbf{2 0 1 7}$ & 18.377 & 42.980 & 261.595 & 96.787 & 16.112 & 20.726 \\
\hline Cresc. \% & $\mathbf{6 , 1 \%}$ & $\mathbf{1 1 6 , 1 \%}$ & $\mathbf{8 3 , 5 \%}$ & $\mathbf{3 1 0 , 8 \%}$ & $\mathbf{- 0 , 3 \%}$ & $\mathbf{8 0 , 9 \%}$ \\
\hline
\end{tabular}

Fonte: BRASIL. INEP. Sinopses Estatísticas do Censo da Educação Superior: 2010 a 2015. Brasília: Disponível em: <http://portal.inep.gov.br/web/guest/sinopses-estatisticas-da-educacaosuperior>. Acesso em 01 jul. 2018.

No tocante ao estado da Paraíba, o crescimento das vagas oferecidas no setor público de ensino, no período de 2010 a 2017, indica 6,1\%, já o setor privado aponta $116,1 \%$ de crescimento, segundo os dados acima. Conforme percebido, quando comparados os números, o setor privado é o que detém o maior crescimento no quesito ofertas de vagas. Em que pese o quantitativo de candidatos inscritos, o setor também teve crescimento em 310\%, entretanto, em todos os anos analisados, verifica-se que o setor público detém o maior número de candidatos que almejam uma vaga na universidade. Com relação ao número de ingressantes, o setor público do estado da Paraíba registrou saldo negativo de $-0,3 \%$, ou seja, a perspectiva de ingressos caiu no último ano analisado (2017), já o setor privado seguiu com aumento de 80,9\%. Portanto, nota-se que em nível local as disparidades do privado sobre o público seguem a tendência geral, decorrentes dos efeitos das políticas de acesso (Fies e Prouni), que atendem, em grade parte, as necessidades do setor privado de ensino.

\section{Considerações finais}

Apresentamos um panorama geral acerca da dinâmica do acesso à educação superior brasileira no âmbito nacional, regional e local. A partir da descrição sobre os processos de expansão identificados nesse nível de ensino, foi possível apreender as disparidades presentes entre o público e privado no contexto neoliberal. 
JENIZE, E; SANTOS, J. B. dos. A dinâmica do acesso à educação superior brasileira: do público ao privado

Verificou-se também uma quantidade significativa de vagas ociosas tanto na rede privada quanto na pública. Segundo Sousa (2010), esse fenômeno evidencia sinais de esgotamento no quadro de expansão do setor privado de ensino, ao mesmo tempo em que a maioria das vagas pouco expressivas são atribuídas ao referido setor. 0 Brasil ainda mantém uma das mais incipientes taxas de escolarização dos jovens com idade entre 18 a 24 anos, conclui o autor (SOUSA, 2010).

A supremacia do setor privado sobre o público no Brasil, Nordeste e Paraíba é um fenômeno resultante dos impactos causados pelas políticas de acesso à educação superior, como no caso do Fies e do Prouni, que atendem, em grade parte, as necessidades do setor privado de ensino. Conforme percebido, verificou-se que essas disparidades são evidenciadas quando comparadas a evolução das matrículas, ofertas de vagas, número de inscritos e ingressantes em nível nacional (Brasil), regional (Nordeste) e local (Paraíba). Nessa direção, a adoção desses programas segue em consonância aos interesses neoliberais.

Considerando o atual cenário político-educacional brasileiro, essas políticas públicas que visam à democratização do acesso poderão, um dia, amenizar as raízes causadoras das desigualdades sociais, ou apenas continuarão surtindo efeitos quantitativos em relação ao acesso à educação superior? Os resultados apresentados, no panorama geral, apontam a respostas um tanto desanimadoras. Contudo, fica em aberto esse questionamento para as próximas investigações.

\section{Referências}

AMARAL, Nelson Cardoso. CHAVES. Política de expansão da Educação Superior no Brasil - o Prouni e o Fies como financiadores do setor privado. Educação em revista. vol. 32 n. 4. Belo Horizonte - MG. oct./dec 2016. Disponível em:

<http://www.reveduc.ufscar.br/index.php/reveduc/article/viewFile/1009/313>. Acesso em: 23 de mai. 2019.

BERNARTT, Maria de Lourdes; DICKMANN, Ivo; SILVA, Maurício Roberto da. Radiografia do Golpe, neoliberalismo e destruição do Estado, "apagamento "dos direitos sociais, “Educação Temer(ária)” e Escola sem Partido. Revista Pedagógica. v. 19, n. 40. 2017. Disponível em:

<https://bell.unochapeco.edu.br/revistas/index.php/pedagogica/article/viewFile/375 9/2135> Acesso em: 23 de mai. 2019. 
JENIZE, E; SANTOS, J. B. dos. A dinâmica do acesso à educação superior brasileira: do público ao privado

BRASIL. Lei de Diretrizes e Bases da Educação Nacional (LDB). Lei número 9394, 20 de dezembro de 1996. Brasília-DF, 1996. Disponível em:

<http://www.planalto.gov.br/ccivil_03/Leis/L9394.htm> Acesso em: 20 de out. 2018.

BRASIL. Decreto no 6.096, de 24 de abril de 2007. Institui o Programa de Apoio a Planos de Reestruturação e Expansão das Universidades Federais - REUNI. BrasíliaDF. 2007. Disponível em: <http://www.planalto.gov.br/ccivil_03/_Ato2007-

2010/2007/Decreto/D6096.htm>. Acesso em: 23 mai. 2019.

BRASIL. Projeto de lei no 3.582, de 18 de maio de 2004. Dispõe sobre a instituição do Programa Universidade para Todos (PROUNI). Brasília-DF 2004. Disponível em: <http://www.camara.gov.br/proposicoesWeb/fichadetramitacao?idProposicao $=25396$ 5.>. Acesso em: 22 de janeiro de 2019.

BRASIL. Ministério da Educação. Termo de Referência. Novo ENEM e Sistema de Seleção Unificada (SISU). 08 abr. 2009. Disponível em:

<https://www.ufpe.br/ufpenova/images/documentos/termo.pdf>. Acesso em: 22 de set. 2018.

BRASIL. Ministério da Educação. Portaria MEC n. 2, de 26 de janeiro de 2010. Institui e regulamenta o Sistema se Seleção Unificado (SISU). NET, 26 jan. 2010. Disponível em: < http://ces.ufpel.edu.br/vestibular/download/2009i/portaria_sisu_diario.pdf > . Acesso em: 02 de dez. 2018.

BRASIL. Lei n. 10260, de 12 de julho de 2001. Dispõe sobre o Fundo de Financiamento ao estudante do Ensino Superior (FIES). Brasília-DF. 2001. Disponível em: <http://www.planalto.gov.br/ccivil_03/leis/leis_2001/l10260.htm.>. Acesso em: 22 de janeiro de 2019.

BRASIL. INEP. Sinopses Estatísticas da Educação Superior. 2010. Disponível em: <http://portal.inep.gov.br/web/guest/sinopses-estatisticas- da-educacao- superior> Acesso em: 10 nov. 2018.

. BRASIL. Sinopses Estatísticas da Educação Superior. 2011. Disponível em: <http://portal.inep.gov.br/web/guest/sinopses-estatisticas- da-educacao- superior> Acesso em: 10 nov. 2018.

BRASIL. Sinopses Estatísticas da Educação Superior. 2012. Disponível em: <http://portal.inep.gov.br/web/guest/sinopses-estatisticas- da-educacao- superior> Acesso em: 10 nov. 2018.

. BRASIL. Sinopses Estatísticas da Educação Superior. 2013. Disponível em: <http://portal.inep.gov.br/web/guest/sinopses-estatisticas- da-educacao- superior> Acesso em: 10 nov. 2018.

BRASIL. Sinopses Estatísticas da Educação Superior. 2014. Disponível em: <http://portal.inep.gov.br/web/guest/sinopses-estatisticas- da-educacao- superior > Acesso em: 10 nov. 2018. 
JENIZE, E; SANTOS, J. B. dos. A dinâmica do acesso à educação superior brasileira: do público ao privado

. BRASIL. Sinopses Estatísticas da Educação Superior. 2015. Disponível em:

<http://portal.inep.gov.br/web/guest/sinopses-estatisticas- da-educacao- superior> Acesso em: 10 nov. 2018.

BRASIL. Sinopses Estatísticas da Educação Superior. 2016. Disponível em: <http://portal.inep.gov.br/web/guest/sinopses-estatisticas- da-educacao- superior> Acesso em: 10 nov. 2018.

. BRASIL. Sinopses Estatísticas da Educação Superior. 2017. Disponível em: <http://portal.inep.gov.br/web/guest/sinopses-estatisticas- da-educacao- superior> Acesso em: 10 nov. 2018.

CARTA CAPITAL. 12 retrocessos em 12 meses de Temer. Disponível em: $<$ https://www.cartacapital.com.br/politica/12-retrocessos-em-12-meses-de-temer $>$. Acesso em: 18 dez. 2018.

CASTELO BRANCO, Uyguaciara Veloso; JEZINE, Edineide; NAKAMURA, Paulo Hideo. Políticas de Expansão, Acesso e Permanência na UFPB (1996 - 2012). In: Colóquio internacional de pesquisas em educação superior: os desafios da graduação e da pósgraduação em tempos de crise. João Pessoa-PB: UFPB, 2017. 18 p. Disponível em: <http://www.coipesu.com.br/upload/trabalhos/2015/6/politicas-de-expansao-acessoe-permanencia-na-ufpb-1996-2012.pdf>. Acesso em: 21 de mar. 2019.

ESTADÃO. Temer veta verba extra para educação básica: ministro fala em orçamento realista. Disponível em:

$<$ https://educacao.estadao.com.br/noticias/geral,temer-veta-verba-extra-paraeducacao-basica-ministro-fala-em-orcamento-realista,70002136603>. Acesso em: 02 jan. 2018.

G1.COM. Veja o impacto do corte de verbas em universidades e institutos federais de 14 estados. Disponível em: <https://g1.globo.com/educacao/noticia/veja-oimpacto-do-corte-de-verbas-em-universidades-e-institutos-federais-de-14estados.ghtml>. Acesso em: 20 dez. 2018.

FELINTO, Jislayne Fidelis. Acesso e permanência na educação superior: a relação entre as condições sociais e a permanência dos ingressos no curso de Pedagogia - Área de Aprofundamento na Educação do Campo na Universidade Federal da Paraíba - UFPB. 2015. 68 f. TCC (Graduação) - Curso de Pedagogia - Educação do Campo, Centro de Educação, Universidade Federal da Paraíba-UFPB, João Pessoa, 2015.

JEZINE, Edineide; BITTAR, Mariluce (Org.). Políticas de Educação Superior no Brasil: expansão, acesso e igualdade social. 1. ed. João Pessoa: Editora da UFPB, 2013.

HOFLING, Eloisa de Mattos. Estado e políticas (públicas) sociais. Cadernos CEDES. vol. 21. n. 55. Campinas. Nov. 2001. Disponível em:

<http://www.scielo.br/scielo.php?script=sci_arttext\&pid=S0101-

$32622001000300003>$ Acesso em: 10 de ago. 2018. 
JENIZE, E; SANTOS, J. B. dos. A dinâmica do acesso à educação superior brasileira: do público ao privado

IBGE - Instituto Brasileiro de Geografia e Estatística. Pesquisa Nacional por Amostra de Domicílios Contínua - PNAD Contínua. IBGE. 2017. Disponível em: <https://www.ibge.gov.br/estatisticas-novoportal/sociais/trabalho/17270-pnadcontinua.html?=\&t=o-que-e $>$ Acesso em: 20 de out. 2018.

MANCEBO, Deise. Educação superior no brasil: expansão e tendências (1995-2014). In: 37a Reunião Nacional da ANPEd - Florianópolis - UFSC, 2015. 20 p. Disponível em: <http://www.anped.org.br/biblioteca/item/educacao-superior-no-brasil-expansao-etendencias-1995-2014> Acesso em: 21 jan. 2019.

PRESTES, Emília; JEZINE, Edineide; SCOCUGLIA, Afonso. Democratização do Ensino Superior Brasileiro: 0 caso da Universidade Federal da Paraíba. Revista Lusófona de Educação n. 21 Lisboa. 2012. Disponível em: <http://revistas.ulusofona.pt/index.php/rleducacao/article/view/3088> Acesso em: 20 de jan. 2018.

REVISTA FÓRUM. 2018: Governo Temer reduzirá em mais de 30\% os investimentos em Educação. Disponível em: <https://www.revistaforum.com.br/2018-governotemer- reduzira-em-mais-de-30-os-investimentos-em-educacao/> Acesso em: 17 dez. 2018.

SANTOS, Boaventura de Sousa. Os processos da globalização. In: SANTOS, Boaventura de Sousa (Org.). A globalização e as ciências sociais. cap. 1, p. 24-103, 4. ed. São Paulo: Cortez, 2011.

SANTOS, Jailson Batista dos. Políticas de Acesso e Permanência à Educação Superior: os impactos do SISU e das políticas de cotas no contexto de inclusão na Universidade Federal da Paraíba: (Relatório) UFPB. 2017. 20 p. Relatório. (PIBIC/UFPB), João Pessoa-PB, 2016-2017.

SOUSA, V. José. Aumento de vagas ociosas na educação superior brasileira (20032008): redução do poder indutor da expansão via setor privado? In: $33^{a}$ - Reunião Anual da ANPEd - Londrina - UEL, 2015. 20 p. 2010. Disponível em: <http://33reuniao.anped.org.br/33encontroapp/webroot/files/file/Trabalhos\%20em \%20PDF/GT11-6552- -Int.pdf> Acesso em: 15 dez. 2018. 


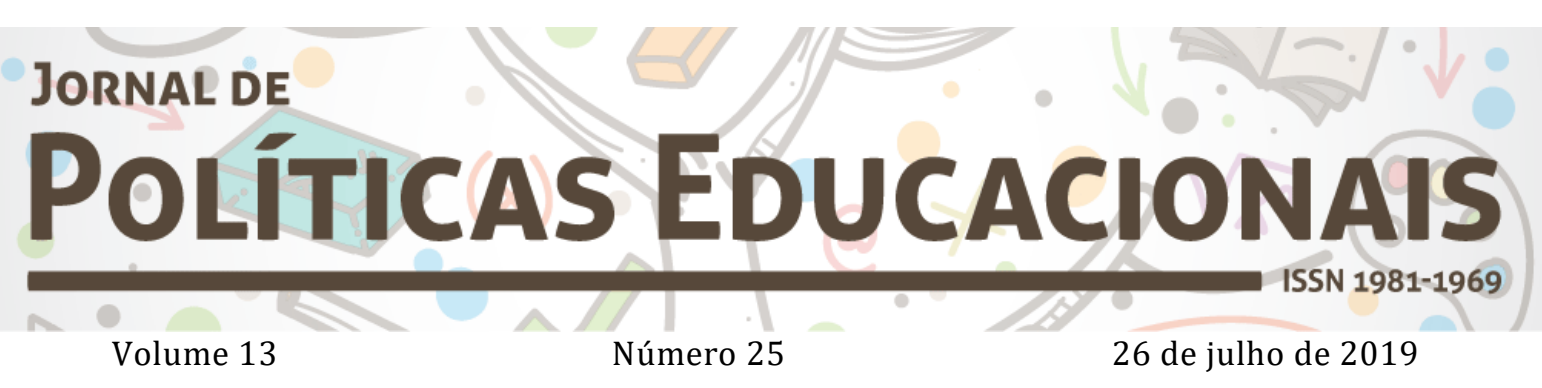

\begin{abstract}
(C)
SOREERIGHISRESERVED O Copyright é retido pelo/a autor/a (ou primeiro coautor) que outorga o direito da primeira publicação ao Jornal de Políticas Educacionais. Mais informação da licença de CreativeCommons encontram-se em http://creativecommons.org/licenses/by-nc-nd/2.5. Qualquer outro uso deve ser aprovado em conjunto pelo/s autor/es e pelo periódico.

JORNAL DE POLÍTICAS EDUCACIONAIS é uma publicação do Núcleo de Políticas Educacionais do Setor de Educação da Universidade Federal do Paraná - NuPE/UFPR, em consórcio com a Linha de Pesquisa em Políticas Educacionais do Programa de Pós-Graduação em Educação - PPGE/UFPR, que aceita colaboração, reservando-se o direito de publicar ou não o material espontaneamente enviado à redação. As colaborações devem ser enviadas ao NuPE/UFPR, conforme orientações contidas nas páginas do periódico na internet: http://revistas.ufpr.br/jpe.
\end{abstract}

\author{
Indexação: \\ BBE - Biblioteca Brasileira de Educação (MEC/INEP) \\ Clase (Base de Datos Bibliográfica de Revistas de Ciencias Sociales y Humanidades) \\ Diadorim - Diretório de Política de Acesso Aberto das Revistas Científicas Brasileiras (IBICT) \\ Google Scholar \\ Index Copernicus \\ Portal de Periódicos (CAPES) \\ SER - Sistema Eletrônico de Revistas da Universidade Federal do Paraná (SER/UFPR) \\ Sumários de Revistas Brasileiras (FUNPEC-RP) \\ DRJI - Directory of Research Journals Indexing
}

(Periódico integralmente disponível apenas em via eletrônica)

Jornal de Políticas Educacionais / Núcleo de Políticas Educacionais da Universidade Federal do Paraná NuPE/UFPR - v.1, n. 1 (1ํs semestre de 2007) - Curitiba: NuPE/UFPR.

Volume 13, número 25 - Julho de 2019

ISSN 1981-1969

1. Educação - Periódicos. 2. Política Educacional - Periódicos. I. NuPE/UFPR

Comitê Editorial:

Elisângela Scaff (UFPR)

Daniela de Oliveira Pires (UFPR)

Ana Lorena Bruel (UFPR)

Conselho Editorial:

Andréa Barbosa Gouveia (UFPR), Ângela Hidalgo (UNICENTRO), Cesar GernominoTello (Universidad Nacional TresFebrero, Argentina),Gladys Beatriz Barreyro (USP), Juca Gil (UFRGS), Jefferson Mainardes (UEPG), João Ferreira de Oliveira (UFG), Luiz Souza Júnior (UFPB), Marcos Edgard Bassi (UFSC), Regina 
JENIZE, E; SANTOS, J. B. dos. A dinâmica do acesso à educação superior brasileira: do público ao privado

Maria Michelotto (UFPR), Robert Verhine (UFBA), Rosana Cruz (UFPI), Rubens Barbosa Camargo (USP), Sebastián Donoso Díaz (Universidad de Talca, Chile), Taís Moura Tavares (UFPR), TheresaAdrião (UNICAMP), Vera Peroni (UFRGS).

Créditos e Agradecimentos:

Revisão de Língua Portuguesa, Abstract e Resumen: PROGRAMA DE APOIO ÀS PUBLICAÇÕES CIENTÍFICAS PERIÓDICAS DA UFPR

Arte e diagramação: TIAGO TAVARES (iagotav@gmail.com)

Jornal de Políticas Educacionais

Universidade Federal do Paraná

Setor de Educação

Núcleo de Políticas Educacionais - NuPE/UFPR

Avenida Sete de Setembro, 2645

$2^{\circ}$ andar, Sala 213

80.230-010 - Curitiba - PR - Brasil

Tel.: 41-3535-6264

jpe@ufpr.br

http://revistas.ufpr.br/jpe 